\title{
EXTRAÇÃO DA BIXINA DO URUCUM UTILIZANDO DIFERENTES TECNOLOGIAS
}

\author{
T. TAHAM ${ }^{1}$, F. A. CABRAL ${ }^{2}$ e M. A. S. BARROZO ${ }^{1}$ \\ 1 Universidade Federal de Uberlândia, Faculdade de Engenharia Química \\ 2 Universidade Estadual de Campinas, Departamento de Engenharia de Alimentos \\ E-mail para contato: thiago.taham@iftm.edu.br
}

\begin{abstract}
RESUMO - A Bixina é o carotenoide mais utilizado pela indústria alimentícia. É extraída convencionalmente das sementes do urucum (Bixa orellana L.) por meio de soluções alcalinas ou solventes orgânicos. Estes métodos de extração produzem bixina de baixa pureza e geram resíduos tóxicos. Este trabalho objetivou comparar entre si diferentes métodos de extração da bixina a partir das sementes do urucum. Os métodos utilizados foram: extração sequencial em leito fixo em três etapas, utilizando $\mathrm{CO}_{2}$ supercrítico na primeira etapa, etanol na segunda e uma mistura de etanol e água (70:30 v/v) na etapa subsequente. Também foram feitas extrações controle com água e clorofórmio nas mesmas condições de pressão e temperatura. As pressões utilizadas foram 400 bar e pressão ambiente; a temperatura de extração foi de $50^{\circ} \mathrm{C}$. Os melhores rendimentos de extração da bixina foram com etanol à pressão ambiente e com uma extração sequencial $\left(\mathrm{ScCO}_{2}\right.$ a 400 bar seguido de etanol à pressão ambiente); os extratos mais puros foram obtidos utilizando-se etanol à pressão ambiente e à 400 bar.
\end{abstract}

\section{INTRODUÇÃO}

O urucum (Bixa orellana L.) é um arbusto característico da floresta amazônica de várzea, cujas sementes produzem um pigmento avermelhado, dependendo de sua concentração em solução (NOBRE et.al., 2006). Nativo da parte tropical sul-americana, seus frutos são usados como ingredientes alimentícios há séculos (Chuyen et al., 2012).

Este corante existe nas formas hidrossolúvel e lipossolúvel, podendo ser empregado em grande número de produtos alimentícios. Seu baixo custo de produção e baixa toxicidade fazem dele um pigmento muito atrativo e conveniente, em substituição a corantes sintéticos (Agner et al., 2004). O corante de urucum é bastante utilizado na indústria alimentícia, mais particularmente em lácteos e carnes. O êxito de uso no setor é devido à comparativa instabilidade dos corantes sintéticos nestas aplicações (Prentice-Hernandez et al., 1993). Também pode ter utilizações nãoalimentícias como remédios, vernizes, corantes, ceras para madeira, tinta para tecidos, couros e fibras em geral (Faria e Costa, 1998).

O principal pigmento do urucum é a bixina, que está contida no revestimento externo da própria semente (pericarpo). A bixina foi isolada pela primeira vez por Boussingault em 1825. Sua fórmula molecular é $\left(\mathrm{C}_{25} \mathrm{H}_{30} \mathrm{O}_{4}\right)$ e apresenta-se convencionalmente de duas formas (Figura 1): a bixina, lipossolúvel, e a norbixina, que é hidrossolúvel (Lima et al., 2001). 


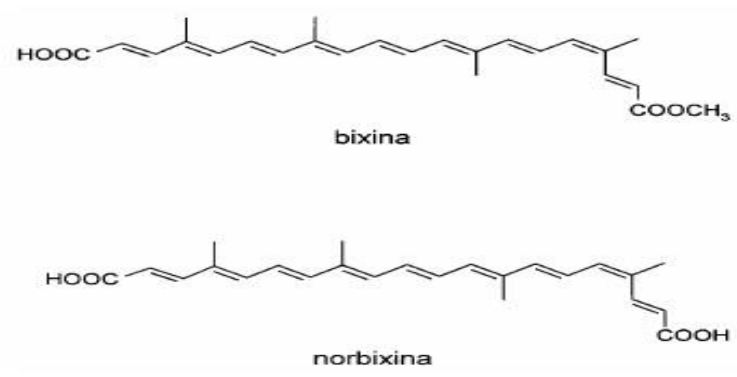

Figura 1: A bixina e a norbixina.

Comercialmente três métodos de extração da bixina do urucum são mais utilizados: a extração alcalina, a extração em óleo, que resulta na remoção da bixina e de outros materiais coloridos, e a extração com solvente, que resulta na forma mais pura do pigmento bixina (Prentice-Hernandez e Rusig, 1992). As extrações com solvente orgânico ou solução alcalina geram resíduos causadores de problemas ambientais, além de requererem uma operação unitária subsequente para remover o solvente ou solução utilizada na extração, elevando o custo total de energia (Albuquerque e Meireles, 2012). A extração em óleo vegetal produz suspensões mais concentradas de pigmentos, mas que podem conter produtos de degradação, haja vista que a extração é realizada em temperaturas maiores que $100^{\circ} \mathrm{C}$ (McKeown e Mark, 1962). Outros métodos de extração podem ser utilizados, tal como a extração com $\mathrm{CO}_{2}$ supercrítico. Não poluente, este método pode ser uma alternativa para evitar os problemas anteriormente citados.

A extração com fluido supercrítico do urucum tem sido estudada com o foco na obtenção da bixina das sementes e vários trabalhos demonstraram que este processo é economicamente viável, ainda que o rendimento seja baixo. Estes estudos demonstraram que a eficiência da extração aumenta com o aumento da pressão e temperatura; que o óleo presente nas sementes atua como um cossolvente e que o uso de solventes orgânicos aumenta o rendimento da extração (Degnan et al., 1991; Chao et al., 1991; Anderson et al., 1997; Nobre et al., 2006; Silva et al., 2008). No processo é utilizado um solvente em condições críticas de temperatura e pressão, ocorrendo um aumento drástico na solubilidade de certos compostos no solvente. Com isso, a extração com fluido supercrítico torna-se uma técnica atrativa para a remoção de compostos de maneira seletiva de sistemas alimentícios complexos (Chao et al., 1991; Pessoa et al., 2006). Este trabalho objetiva, então, investigar métodos que aumentem o rendimento da extração da bixina das sementes do urucum, combinando a tecnologia supercrítica com outros métodos de extração que apresentem baixo impacto ambiental, de modo a incrementar os resultados obtidos e tornar o processo economicamente mais atrativo.

\section{METODOLOGIA}

As sementes de urucum foram obtidas na cidade de Rio Vermelho (Vale do Jequitinhonha - MG) e armazenadas em sacos de polietileno de cor escura em câmara fria $\left(\mathrm{a}-18^{\circ} \mathrm{C}\right)$ até que os experimentos fossem conduzidos.

\subsection{Caracterização das Sementes}

As sementes foram caracterizadas em termos de sua umidade e teor de bixina. A umidade foi determinada pelo método de estufa a $105^{\circ} \mathrm{C}$ - método AOAC 931.04 (1997). 
Para a determinação do teor de bixina no extrato obtido e nas sementes foi utilizado o método espectrofotométrico recomendado pela FAO (Food and Agriculture Organization of the United Nations, 2006). A absorbância das amostras foi medida em cubeta de quartzo de $1 \mathrm{~cm}$, em comprimento de onda de $487 \mathrm{~nm}$, utilizando um espectrofotômetro UV visível (Perkin Elmer Lambda 40). O teor de bixina nas amostras foi calculado utilizando a Lei de Lambert-Beer, utilizando $E_{1 \mathrm{~cm}}^{1 \%}=3090(\mathrm{FAO}, 2006)$, por meio da Equação 1:

$$
\operatorname{Bixina}(\%)=\frac{A * V_{1} * \ldots * V_{n}}{E * m_{\operatorname{amostra}} * V^{\prime}{ }_{1} * \ldots * V_{n}^{\prime}}
$$

em que:

$\mathrm{A}=$ absorbância média das amostras (adimensional); $\mathrm{V}_{\mathrm{i}}=$ Volume da diluição $(\mathrm{i}=1,2, \ldots, \mathrm{n})$; $\mathrm{E}=$ Coeficiente de absortividade (igual a 3090 para a Bixina) $\mathrm{m}_{\text {amostra }}=$ massa da amostra utilizada na análise, em gramas $V^{\prime}{ }_{i}=$ Volume da alíquota para diluição $(i=1,2, \ldots, n)$.

\subsection{Extração Convencional da Bixina}

Para a determinação do teor de bixina nas sementes de urucum, foi feita uma extração convencional com clorofórmio a $50^{\circ} \mathrm{C}$. Esta condição foi escolhida para a extração baseada nos trabalhos de Silva et al. (1994) cujos resultados mostram que, além do bom desempenho do clorofórmio como solvente, temperaturas abaixo de $80^{\circ} \mathrm{C}$ causam mínima degradação na bixina. Para efeito de comparação, a mesma extração foi feita utilizando água, também a $50^{\circ} \mathrm{C}$. As extrações foram feitas em uma célula de equilíbrio, cujo conteúdo ficou sob constante agitação por meio de um agitador magnético. A célula de equilíbrio foi acoplada a um aparelho de soxhlet, para impedir a perda de substâncias voláteis, sendo o banho termostatizado do soxhlet mantido a $5^{\circ} \mathrm{C}$.

\subsection{Extração em Leito Fixo}

Os experimentos em leito fixo foram realizados em uma unidade experimental de bancada, no Laboratório de Extração, Termodinâmica Aplicada e Equilíbrio (EXTRAE) da Faculdade de Engenharia de Alimentos da Unicamp. A Figura 2a apresenta um diagrama esquemático da unidade experimental utilizada e a Figura 2 b representa a unidade em si.
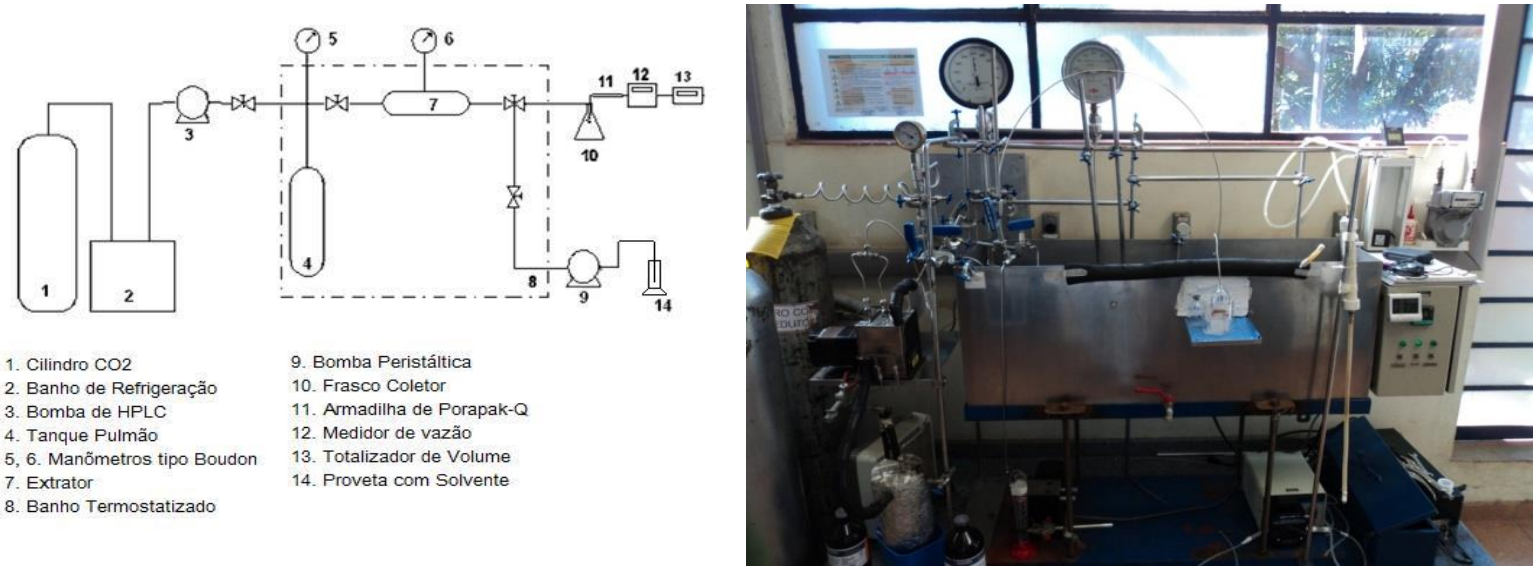

Figuras 2(a,b), em que (a) representa o esquema e (b) a fotografia da unidade experimental 
Foram colocadas $15 \mathrm{~g}$ de sementes inteiras de urucum no extrator, completando o volume com pérolas de vidro. Esta montagem deixa o sistema completamente cheio, fazendo com que o solvente utilizado passe entre as partículas, facilitando a solubilização dos compostos de interesse. Após a montagem, o banho era completado com água até a cobertura do extrator e das válvulas. A temperatura de todas as extrações foi de $50^{\circ} \mathrm{C}$. Nos experimentos conduzidos à alta pressão (400 bar) foi realizado um teste de pressurização para verificar vazamentos. Nos experimentos à pressão ambiente, uma pressão de 5 bar era fornecida ao sistema somente para garantir o preenchimento do leito, otimizando o contato entre o solvente e as sementes.

Em um segundo momento foram realizadas extrações sequenciais $(\mathrm{S})$, com o objetivo de determinar a cinética de obtenção da bixina. Os solventes utilizados foram, sequencialmente, o $\mathrm{CO}_{2}$, o etanol e uma mistura entre etanol e água (70:30 v/v), injetados no sistema sem a renovação das sementes, caracterizando a extração sequencial. Esta extração foi realizada em triplicata. Nos dois primeiros experimentos da triplicata, amostras foram retiradas ao longo do tempo de modo a construir uma curva de extração. No terceiro experimento da triplicata, uma amostra foi recolhida somente no tempo final de cada etapa da extração. A última fase da extração (SA) foi realizada utilizando a metodologia de Albuquerque e Meireles (2012), e consistiu em uma extração sequencial com $\mathrm{CO}_{2}$ supercrítico seguida de extração com solvente à pressão ambiente. Nesta etapa foram utilizados como solventes o etanol e a mistura entre etanol e água $(70: 30 \mathrm{v} / \mathrm{v})$. A Tabela 1 resume as condições operacionais dos experimentos realizados no leito fixo.

Tabela 1 - Condições experimentais

\begin{tabular}{|c|c|c|c|c|c|}
\hline Código & Solvente & Vazão Solvente & $\mathbf{T}\left({ }^{\circ} \mathbf{C}\right)$ & $\mathbf{P}$ (bar) & $t$ (min) \\
\hline U1 & $\mathrm{CO}_{2}$ & $1,5 \mathrm{~L} / \mathrm{min}$ & 50 & 400 & 300 \\
\hline $\mathrm{U} 2$ & Etanol & $0,5 \mathrm{~mL} / \mathrm{min}$ & 50 & 5 & 540 \\
\hline U3 & Etanol & $0,5 \mathrm{~mL} / \mathrm{min}$ & 50 & 400 & 540 \\
\hline $\mathrm{U} 4$ & Etanol-Água & $0,5 \mathrm{~mL} / \mathrm{min}$ & 50 & 5 & 540 \\
\hline U5 & Etanol-Água & $0,5 \mathrm{~mL} / \mathrm{min}$ & 50 & 400 & 540 \\
\hline \multirow{3}{*}{ S1 } & $\mathrm{CO}_{2}$ & $1,5 \mathrm{~L} / \mathrm{min}$ & 50 & 5 & 210 \\
\hline & Etanol & $0,5 \mathrm{~mL} / \mathrm{min}$ & 50 & 400 & 360 \\
\hline & Etanol-Água & $0,5 \mathrm{~mL} / \mathrm{min}$ & 50 & 5 & 360 \\
\hline \multirow{3}{*}{ S2 } & $\mathrm{CO}_{2}$ & $1,5 \mathrm{~L} / \mathrm{min}$ & 50 & 400 & 210 \\
\hline & Etanol & $0,5 \mathrm{~mL} / \mathrm{min}$ & 50 & 5 & 360 \\
\hline & Etanol-Água & $0,5 \mathrm{~mL} / \mathrm{min}$ & 50 & 400 & 360 \\
\hline \multirow{3}{*}{ S3 } & $\mathrm{CO}_{2}$ & $1,5 \mathrm{~L} / \mathrm{min}$ & 50 & 400 & 210 \\
\hline & Etanol & $0,5 \mathrm{~mL} / \mathrm{min}$ & 50 & 5 & 360 \\
\hline & Etanol-Água & $0,5 \mathrm{~mL} / \mathrm{min}$ & 50 & 400 & 360 \\
\hline \multirow{2}{*}{ SA1 } & $\mathrm{CO}_{2}$ & $1,5 \mathrm{~L} / \mathrm{min}$ & 50 & 400 & 120 \\
\hline & Etanol & $0,5 \mathrm{~mL} / \mathrm{min}$ & 50 & 5 & 420 \\
\hline \multirow{2}{*}{ SA2 } & $\mathrm{CO}_{2}$ & $1,5 \mathrm{~L} / \mathrm{min}$ & 50 & 400 & 120 \\
\hline & Etanol-Água & $0,5 \mathrm{~mL} / \mathrm{min}$ & 50 & 5 & 420 \\
\hline
\end{tabular}

Após a passagem de $\mathrm{CO}_{2}$ pelo leito, coletou-se o extrato em frasco de penicilina, previamente pesado em balança analítica. $\mathrm{O} \mathrm{CO}_{2}$ que passava pelo extrator era conduzido a um medidor de vazão e totalizador, quantificando sua passagem pelo sistema. A tubulação era, então, lavada com etanol para garantir a retirada do extrato aderido às suas paredes. A coleta de amostras 
nas extrações com os solventes líquidos eram realizadas analogamente. As amostras contidas nos frascos de penicilina, devidamente pesados e identificados, eram secas em evaporador rotativo a $50^{\circ} \mathrm{C}$ utilizando vácuo de $700-750 \mathrm{mmHg}$ e novamente pesados, para a obtenção da massa dos extratos. Todos os frascos eram, então, armazenados a $-18^{\circ} \mathrm{C}$ protegidos da ação da luz, até que as análises fossem conduzidas.

\section{RESULTADOS}

\subsection{Caracterização das Sementes}

A umidade média das sementes foi de $11,5 \%$ (base úmida).

O teor de bixina das sementes foi determinado a partir da extração convencional até o total esgotamento das sementes. As extrações convencionais utilizando, separadamente, água e clorofórmio resultaram no seguinte perfil de extração global apresentado na Tabela 2.

Tabela 2- Resultado da determinação do teor de bixina em extração com água e clorofórmio

\begin{tabular}{lccccc}
\hline Solvente & $\begin{array}{c}\mathbf{M}_{\text {matéria-prima }} \\
(\mathbf{g})\end{array}$ & $\begin{array}{c}\mathbf{M}_{\text {extrato }} \\
(\mathbf{g})\end{array}$ & $\begin{array}{c}\mathbf{M}_{\text {bixina }} \\
(\mathbf{g})\end{array}$ & \% bixina & $\begin{array}{c}\text { Relação } \\
\text { ( }\end{array}$ \\
\hline Água & 1,0519 & 0,4494 & 0,0053 & 1,18 & 0,0050 \\
\hline Clorofórmio & 1,0563 & 0,3638 & 0,0090 & 2,47 & 0,0085 \\
\hline
\end{tabular}

A extração com clorofórmio foi considerada neste trabalho como a que atingiu $100 \%$ de eficiência. $\mathrm{O}$ teor de bixina foi calculado tendo como base a massa de extrato obtido, e não a massa total das sementes. $\mathrm{O}$ teor de bixina encontrado no extrato do urucum foi, então, de 2,47\%.

\subsection{Extração em Leito Fixo}

Cinco extrações em etapa única (U) foram conduzidas; seus tempos de duração foram distintos mediante resultados obtidos em extrações preliminares. A Tabela 3 mostra os resultados obtidos em cada uma das extrações.

Tabela 3 - Resultados das extrações em etapa única (U)

\begin{tabular}{llcccccc}
\hline Exp. & Solvente & $\begin{array}{c}\mathbf{P} \\
\text { (bar) }\end{array}$ & $\begin{array}{c}\mathbf{M}_{\text {matéria- }} \\
\text { prima }\end{array}$ & $\begin{array}{c}\mathbf{M}_{\text {extrato }} \\
(\mathbf{g})\end{array}$ & $\begin{array}{c}\mathbf{M}_{\text {bixina }} \\
(\mathbf{g})\end{array}$ & $\begin{array}{c}\text { \% } \\
\text { bixina }\end{array}$ & $\begin{array}{c}\mathbf{M}_{\text {bixina }} / \mathbf{M}_{\text {matéria- }} \\
\text { prima }\end{array}$ \\
\hline $\mathrm{U} 1$ & $\mathrm{ScCO}_{2}$ & 400 & 15,1259 & 0,2591 & 0,0129 & 4,98 & 0,0009 \\
\hline $\mathrm{U} 2$ & Etanol & 5 & 15,8366 & 0,9243 & 0,1328 & 14,37 & 0,0084 \\
\hline $\mathrm{U} 3$ & Etanol & 400 & 15,0177 & 0,6958 & 0,0777 & 11,17 & 0,0052 \\
\hline $\mathrm{U} 4$ & Etanol/Água & 5 & 15,2854 & 1,3160 & 0,0842 & 6,40 & 0,0055 \\
\hline $\mathrm{U} 5$ & Etanol/Ấgua & 400 & 15,0017 & 0,9535 & 0,0496 & 5,20 & 0,0033 \\
\hline
\end{tabular}

Todos os percentuais de bixina obtidos foram superiores ao encontrado na Tabela 2. Isto se deve ao fato de que, na extração convencional, o experimento foi conduzido até o esgotamento da semente, sendo arrastados, além dos pigmentos, todos os outros componentes do pericarpo. Tal fato contribuiu para aumentar a massa total do extrato obtido e reduzir o percentual de bixina presente neste. 
A extração U1 mostrou ser a menos capaz de extrair os compostos a partir das sementes inteiras. Na primeira hora, extraiu-se o óleo do urucum, de cor vermelho intenso, seguido por uma decrescente extração de pigmentos. Comparando-se as extrações (U2 e U3; U4 e U5), percebe-se que o aumento da pressão causa um efeito inverso na eficiência da extração. A massa do extrato global obtido é menor em ambos os casos e o teor de bixina também apresenta-se menor. $\mathrm{O}$ aumento da polaridade do solvente também não se mostrou eficaz para aumentar a eficiência na extração: apesar de a mistura com água aumentar o rendimento global, os teores de bixina foram menores tanto em massa quanto em porcentagem. Este resultado mostra a capacidade da água em extrair outros compostos da semente, além da bixina. Os resultados da Tabela 3 mostraram que a extração da bixina, nas condições testadas, foi mais eficiente a baixas pressões e utilizando o etanol como solvente.

Três extrações sequenciais (S) também foram conduzidas. Os solventes foram inseridos na ordem em que são apresentados na Tabela 4, que mostra os resultados obtidos.

Tabela 4 - Resultados das extrações sequenciais (S)

\begin{tabular}{|c|c|c|c|c|c|c|c|}
\hline Exp. & Solvente & $\begin{array}{c}\mathbf{P} \\
\text { (bar) }\end{array}$ & $\begin{array}{l}\mathbf{M}_{\text {matéria- }} \\
\text { prima }(\mathbf{g})\end{array}$ & $\begin{array}{c}\mathbf{M}_{\text {extrato }} \\
(\mathrm{g})\end{array}$ & $\begin{array}{c}M_{\text {bixina }} \\
(\mathbf{g})\end{array}$ & $\begin{array}{c}\% \\
\text { bixina }\end{array}$ & $\begin{array}{c}\mathbf{M}_{\text {bixina }} / \mathbf{M}_{\text {matéria- }} \\
\text { prima }\end{array}$ \\
\hline \multirow{3}{*}{ S1 } & $\mathrm{ScCO}_{2}$ & \multirow{3}{*}{400} & \multirow{3}{*}{14,9153} & 0,2525 & 0,0121 & 4,79 & \multirow{3}{*}{0,0062} \\
\hline & Etanol & & & 0,5002 & 0,0607 & 12,14 & \\
\hline & Etanol /água & & & 0,4506 & 0,0196 & 4,35 & \\
\hline \multirow{3}{*}{$\mathrm{S} 2$} & $\mathrm{ScCO}_{2}$ & \multirow{3}{*}{400} & \multirow{3}{*}{15,1358} & 0,2591 & 0,0085 & 3,28 & \multirow{3}{*}{0,0068} \\
\hline & Etanol & & & 0,4979 & 0,0714 & 14,34 & \\
\hline & Etanol /água & & & 0,4314 & 0,0234 & 5,42 & \\
\hline \multirow{3}{*}{ S3 } & $\mathrm{ScCO}_{2}$ & \multirow{3}{*}{400} & \multirow{3}{*}{15,066} & 0,2691 & 0,0113 & 4,20 & \multirow{3}{*}{0,0067} \\
\hline & Etanol & & & 0,4947 & 0,0663 & 13,40 & \\
\hline & Etanol /água & & & 0,4339 & 0,0242 & 5,58 & \\
\hline
\end{tabular}

O tempo total destas extrações foi o maior dentre todos (15 horas e 30 minutos), o que foi feito para garantir um tempo suficiente de contato entre as sementes e o respectivo solvente puro haja vista que, no período de troca dos solventes, ocorre uma mistura entre eles no extrator. Apesar do tempo maior de extração, nenhuma resposta destes três experimentos foi capaz de superar a relação entre massa de bixina obtida e massa de matéria-prima utilizando o etanol a baixa pressão em etapa única.

A relação entre massa de bixina obtida e a massa de sementes utilizada na extração demonstra boa repetibilidade entre as três extrações, realizadas nas mesmas condições operacionais. As maiores massas de bixina obtidas, bem como os maiores teores desta nos extratos foram obtidos com o solvente etanol, conforme mostraram, também, as extrações em etapa única. Os altos percentuais de bixina dos extratos etanólicos após a extração supercrítica demonstram que uma grande parte do corante não é removida na primeira etapa da extração. Resultados similares foram obtidos nos trabalhos de Albuquerque e Meireles (2012) e Rodrigues et al. (2014).

As últimas três extrações realizadas (SA) também podem ser consideradas como extrações sequenciais. A diferença entre elas (SA) e as extrações sequenciais (S), foi a variação das condições operacionais dentro da mesma corrida. A Tabela 5 mostra os resultados obtidos. 
Tabela 5 - Resultados das extrações sequenciais em condições distintas (SA)

\begin{tabular}{|c|c|c|c|c|c|c|c|}
\hline Exp. & Solvente & P (bar) & $\begin{array}{l}\mathbf{M}_{\text {matéria- }} \\
\text { prima }(\mathbf{g})\end{array}$ & $\begin{array}{c}\mathbf{M}_{\text {extrato }} \\
(\mathbf{g})\end{array}$ & $\begin{array}{c}\mathbf{M}_{\text {bixina }} \\
(\mathrm{g})\end{array}$ & $\begin{array}{c}\% \\
\text { bixina }\end{array}$ & $\begin{array}{c}\mathbf{M}_{\text {bixina }} / \mathbf{M}_{\text {matéria- }} \\
\text { prima }\end{array}$ \\
\hline \multirow{2}{*}{ SA1 } & $\mathrm{ScCO}_{2}$ & 400 & \multirow{2}{*}{15,8270} & 0,2736 & 0,0023 & 8,40 & \multirow{2}{*}{0,0070} \\
\hline & Etanol & 5 & & 1,1102 & 0,1089 & 9,81 & \\
\hline \multirow{2}{*}{ SA2 } & $\mathrm{ScCO}_{2}$ & 400 & \multirow{2}{*}{15,5874} & 0,2498 & 0,0020 & 8,00 & \multirow{2}{*}{0,0022} \\
\hline & Etanol /água & 5 & & 1,7663 & 0,0324 & 1,83 & \\
\hline
\end{tabular}

Assim como encontrado no trabalho de Albuquerque e Meireles (2012) e Rodrigues et al. (2014), a aplicação da extração supercrítica como pré-tratamento das sementes e posterior extração a baixa pressão com solvente aumentou a quantidade de bixina obtida. $O$ resultado não foi, entretanto, superior ao obtido com a extração etanólica à baixa pressão, ainda que o tempo total das duas etapas tenha sido o mesmo que o da extração etanólica. Pode-se considerar então que, dentre as condições testadas, nenhum método foi mais eficiente do que a extração com etanol a baixa pressão.

\section{CONCLUSÕES}

Neste estudo alguns métodos de extração foram testados e combinados entre si, com o foco na obtenção da bixina do urucum. Nenhuma das combinações testadas foi mais eficiente do que a extração etanólica sem utilizar altas pressões. Esta condição foi responsável pela maior obtenção de bixina em relação à massa inicial das sementes dentre todas as condições testadas. Além disso, ainda conseguiu apresentar os maiores percentuais de bixina no extrato obtido, caracterizando-se como a bixina mais pura obtida dentre as condições testadas.

\section{REFERÊNCIAS}

AGNER, A.R.; BARBISAN, L.F.; SCOLASTICI, C.; SALVADORI, D.M.F. Absence of carcinogenic and anticarcinogenic effects of annatto in the rat liver medium-term assay. Food and Chem. Toxicol., v.42, p.1687-1693, 2004.

ALBUQUERQUE, C. L.; MEIRELES, M. A. de A. Defatting of annatto seeds using supercritical carbon dioxide as a pretreatment for the production of bixin: Experimental, modeling and economic evaluation of the process. The Journal of Supercritical Fluids, v. 66, p. 86-95, 2012.

ANDERSON, S. G.; NAIR, M. G.; CHANDRA, A.; MORRISON, E. Supercritical fluid carbon dioxide extraction of annatto seeds and quantification of trans-Bixin by high pressure liquid chromatography. Phytochemical Analysis, v. 8. p. 247-249, 1997

AOAC INTERNATIONAL. Official methods of analysis. $16^{\mathrm{a}}$ ed., $3^{\mathrm{a}}$ rev. Gaitherburg: Published by AOAC International,. v.2, cap. 32, p.1-43, 1997.

CHAO, R. R.; MULVANEY, S. J.; SANSON, D. R.; HSIEH, F.; TEMPESTA, M. S. Supercritical $\mathrm{CO}_{2}$ extraction of annatto (Bixaorellana) pigments and some characteristics of the color extracts. J. Food Science, v. 56, p. 80-83, 1991. 


\section{9 a 22 de outubro de 2014 \\ Florianópolis/SC}

CHUYEN, H. V.; NGOC HOI, N. T. \& EUN J-B. Improvement of bixin extraction yield and extraction quality from annatto seed by modification and combination of different extraction methods. Inter. J. Food Sci. Technol., v. 47, p. 1333-1338, 2012.

DEGNAN, A. J.; VON ELBE, J. H.; HARTEL, R.W. Extraction of annatto seed pigment by supercritical $\mathrm{CO}_{2}$. J. Food Science, v. 56, p. 1656-1659, 1991.

FOOD AND AGRICULTURE ORGANIZATION OF THE UNITED NATIONS (FAO). Combined Compendium of Food Additive Specifications, in: $67^{\text {th }}$ Joint FAO/WHO Expert Committee on Food Additives, v.3, p. 11, 2006.

FARIA, L.J.G.; COSTA, C.M.L. Tópicos Especiais em Tecnologia de Produtos Naturais. UFPA, Série Poema, n.7, p. 302, 1998.

GIRIDHAR, P.; VENUGOPALAN, A.; PARIMALAN, R. A Review on Annatto Dye Extraction, Analysis and Processing - A Food Technology Perspective. J. Sci. Res. \& Rep. v. 3(2), p. 327-348, 2014.

LIMA, L.R.P.; OLIVEIRA, T.T.; NAGEM, T.J.; PINTO, A.S.; STRINGHETA, P.C.; TINOCO, A.L.A.; SILVA, J.F. Bixina, Norbixina e Quercitina e seus efeitos no metabolismo lipídico de coelhos. Braz. J. Vet. Res. An. Sc., v.38 (4), p. 196 - 200, 2001.

MCKEOWN, G. G.; MARK, E. The composition of oil-soluble annatto food colors. Journal of the AOAC. v. 45 (3), p. 761-766, 1962.

NOBRE, B. P.; MENDES, R. L.; QUEIROZ, E. M.; PESSOA, F. L. P.; COELHO, J. P.; PALAVRA, A. F. Supercritical carbon dioxide extraction of pigments from Bixa orellana seeds (experiments and modeling). Braz. J. Chem. Eng., v. 23(2), p.251-258, 2006.

PESSOA, F. I. P.; QUEIROZ, E. M .; COELHO, J. P.; NOBRE, B. P.; MENDES, R. L.; CARDOSO, M. A. T.; PALAVRA, A. F. Estudo do processo de obtenção de produtos de urucum utilizando fluidos supercríticos. Simpósio Brasileiro do Urucum . João Pessoa, PB. Anais ... Emepa, 2006.

PRENTICE-HERNANDEZ, C.; RUSIG, O. Extrato de urucum (Bixa orellana L.) obtido utilizando álcool etílico como solvente. Arquivos de Biologia e tecnologia, v. 35 (1), p.63-74, 1992.

RODRIGUES, L. M.; ALCÁZAR-ALAY, S. C.; PETENATE, A. J.; MEIRELES, M. A. A. Bixin extraction from defatted annatto seeds. C. R. Chimie, v. 17, p. 268-283, 2014.

SILVA, G. F.; GAMARRA, F. M. C.; OLIVEIRA, A. L.; CABRAL, F. A. Extraction of bixin from annatto seeds using supercritical carbon dioxide. Brazilian J. Chemical Engineering, v. 25, p. 419-426, 2008.

SILVA, G. F; CAVALCANTI, S. A.; SOBRAL, M. C. Extração de corantes do urucum II. Anais da Associacao Brasileira de Quimica, v. 43(1-2), p. 58-64, 1994. 